\title{
Plowing the Zen Field: Trends Since 1989 and Emerging Perspectives
}

\author{
Michel Mohr* \\ University of Hawai'i at Mānoa
}

\begin{abstract}
This survey article focuses on the object and scope of Zen Studies, and on trends visible since 1989. It argues that scholarship about Chan, Zen, Chan, Seon, and Thiên should be more closely integrated with Buddhist Studies, and that the boundaries of this field need to be expanded. Critical and epistemologically aware scholarship only emerged in the 1990s. Hence, scholars need to make a concerted effort in devoting more attention to methodological issues. This in turn ought to be skillfully distilled to non-academic audiences.
\end{abstract}

\section{Introduction}

More than ever pop culture appears to have appropriated the word "Zen," so that it now conveys images of cool aloofness only remotely connected to the traditions from which it emerged. Among factors reinforcing this tendency, we may point out the huge gap still separating the academic study of Zen, traditional Buddhist lineages focusing on meditation, ${ }^{1}$ and the perception of these lineages in the public. This survey article turns the spotlight on the academic study of Zen, asking to what extent it is legitimate to speak of Zen Studies as a "field," and examining some new trends visible since 1989. Instead of simply providing a review of the state of the field, it highlights some of the issues in what many students take for granted when directing their attention to the multifarious and often inchoate area they call "Zen."

This implies first discussing how to delineate this elusive object of study called "Zen" in a meaningful way, without pretending to redefine the boundaries. The ancillary question we need to address is whether isolating the category "Zen" from its Buddhist context proves beneficial at all. We will then examine some scholarly achievements of the last few decades, directing our attention to what has been gained and what remains to be done. Such questioning will lead us to list areas particularly in need of further research.

As this article often mentions biases informing Zen Studies, it is fair to disclose my own research background. Most of my publications have focused on Japanese religious and intellectual history spanning between the Tokugawa period $(1600-1867)^{2}$ and the Taishō era (1912-1926). While fully aware of the Chinese roots of Chan and of the significance of Korean and Vietnamese developments, my long exposure to Japanese scholarship certainly informs the way I perceive Zen Studies and the Zen traditions. For instance, references to the paralyzing effects of sectarian consciousness and parochialism result from first-hand observation of such proclivity in Japan, and do not target academics in the West or in other parts of Asia.

Let me also add the disclaimer that I do not have any authority for speaking in the name of the Zen traditions themselves, and that this piece reflects a purely scholarly 
perspective. Lastly, although significant research appears in various other languages, this review is limited to publications in English. It mostly covers some landmark monographs containing bibliographies that should enable students to begin their exploration of particular topics. Students should also remember to utilize the wealth of articles found in specialized journals.

\section{Object and Scope of the So-called Zen Studies}

Let us begin by facing the delicate issue of whether we can view Zen Studies as constituting a "field" and, if so, how the object and scope of this type of research could be delineated. We may be tempted to deflect the first question by saying that the existence of this article and of similar pieces are in themselves proof that the field exists. One could likewise argue that asking such a question is mere sophistry, and that decades of publication on the topic of Zen should dispel any doubt. Yet, it is not so easy to dismiss this interrogation, because one could counter that the Zen category of scholarship was fabricated for proselytizing purposes, and that its uncritical acceptance is the result of mere naiveté. In any case, any such challenge cannot be properly taken up as long as the supposed field's boundaries remain imprecise.

For example, how should we categorize the study of meditation in the Japanese Tendai tradition? Does it exclusively belong to "Tendai Studies"? In this case, how should we treat the teachings of Myōan Yōsai (1141-1215), originally a Tendai monk, who introduced the Rinzai Zen tradition to Japan? What about the three-pronged practice (Sansh $\bar{u}$ Kengaku, including Zen, Tendai, and Shingon) that he advocated at Kenninji, the monastery built for him in Kyoto? Even such simple cases of overlap between distinct traditions suggest the extent to which sectarian boundaries are porous, and indicate that reality on the ground was and remains more complex than the neatly defined categories in which we would like to assign its components. This is the first awareness we should reach before proceeding further: sectarian categories not only are limited in their usefulness but also contribute to obscuring the complexity of actual religious and intellectual interactions.

The stiffness of such categories also largely results from religious policies devised after the 1868 Meiji Restoration, which included the short-lived creation of a "Zen" sect in 1873. This attempt by the Japanese Ministry of Doctrine to centralize the administrative structure and gain a better control on the Buddhist schools resulted in the arbitrary merging of the Sōtō, Rinzai, and Ōbaku traditions. Finally, in 1874 the government had to revert its decision and to recognize the independence of the Sōtō and Rinzai denominations. Two years later, the Ōbaku school also gained independence. In any case, once we have identified the root problem involved in the sectarian labels (the fact that they are the product of administrative concerns and of these institutions' interest in promoting their own tradition), we may agree that the usage of "Zen Studies" as a scholarly category can be misleading and could even be considered detrimental to the study of Buddhism's multifariousness. Fortunately, this does not imply that our task is hopeless, as there is room for more flexible approaches taking diversity into account and reintegrating Zen Studies into its proper position.

For this, we need first to differentiate between the usage of the word zen as a generic term for "meditation" (often indicated by using the lowercase) and its usage to indicate the particular religious movement that emerged in China and referred to itself as Chan (the Chinese character pronounced Zen in Japanese, Seon in Korean, and Thiên in Vietnamese). ${ }^{3}$ Let me formulate the paradoxical statement that "zen does not exclusively 
belong to the Zen traditions" to illustrate this crucial point. To clarify this, one needs to refer to the transition between Indian and Chinese Buddhism. In Pali, an Indic language close to the idiom used by the historical Buddha, ${ }^{4}$ the various degrees of meditative absorption were indicated by speaking of various jhänas or "concentrations." Non-Buddhist ascetics also cultivated these mental states, known in Sanskrit as the dhyānas. After the introduction of Buddhism into China in the first century of the Common Era ${ }^{5}$ the word jhanna was phonetically transcribed in Chinese as channa, and eventually chan, the first half of the compound, became a word in itself.

What is important here is that already in Pali and in Sanskrit the technical terms jhāna and dhyana could be used in two distinctive ways: they either referred to specific states of meditative absorption, or to meditation in general. ${ }^{6}$ In China, practitioners did not seem especially interested in the elaborate description of nine meditative stages, but meditation was central to all Mahāyana schools and corresponded to the fifth of the six "perfections" (Sk. parramita $\vec{a}$ to be cultivated by every Buddhist. An additional layer of complexity emerged when some Chinese Buddhist practitioners began identifying their lineage as the "Chan tradition" (chanzong), a particular blend of Buddhist practice focused on meditation. This tradition supposedly had been transmitted since the time of the historical Buddha and was brought to China by the charismatic teacher Bodhidharma. The materialization of such narrative goes back to a stele engraved in 690 (Cole 2009, p. 73). ${ }^{7}$

Mentioning the construction of the Bodhidharma story leads us to examine recent advances in research about the formative period John McRae characterizes as "protoChan," which roughly corresponds to the sixth and seventh centuries CE (McRae 2003, p. 13). To summarize a long string of research that may still evolve, and at the risk of disappointing those who find the early narratives enthralling, the vast majority of stories surrounding Bodhidharma and the formative period should be considered as pious legends, which emerged several centuries after the events they claim to depict. Cole's suggestion that "the rhetorical devices that turned into Chan were developed, in part, to solve the basic problem of China's distance from India and the beloved Buddha" provides the type of sophisticated perspective students need to emulate (Cole 2009, p. 74).

Before proceeding further, let us venture to provide a preliminary answer to three of the questions raised at the beginning of this article. Concerning the legitimacy of Zen Studies as an academic field, I suggest that a healthy approach begins by acknowledging that this discipline is scrutinizing a multitude of historically determined contexts, whose lumping into a single - supposedly homogeneous - entity called "Zen" is problematic in the first place. A lucid examination of how westerners have been informed about this topic since the early 20 th century indicates that much of the information was contaminated with naive views on the uniqueness of Zen and Japanese culture. As indicated by the above example of meditation in the Japanese Tendai tradition and the case of Myōan Yōsai, so-called Zen Studies would often benefit from being reintegrated into the fold of Buddhist Studies. In other words, the humble recognition that the academic study of Zen is nothing more than a subset of Buddhist Studies would go a long way toward its integration into a larger body of scholarship, from which it should never have been divorced.

To settle this question, one may emphasize that from a methodological perspective nothing seems to warrant isolating Zen Studies from Buddhist Studies. From the textual or philological standpoint, it is true that familiarity with specific forms of literature and practices is necessary. Yet, aside from encounter dialogs and koans, the language used in Chan and Zen anthologies does not significantly differ from the language used in any other Buddhist text. One possible exception would be the proportion of Chinese vernacular language that found its way into Chan recorded sayings since the Tang dynasty. Nevertheless, even this feature 
can be considered as nothing more than a certain kind of technical vocabulary, which does not justify creating an independent field. If anything, the need for specialists might rather be that of linguists who focus on the vernacular language. ${ }^{8}$

The second issue dealt with how to circumscribe the object of Zen Studies - be it considered as a subset of Buddhist Studies or as a field in its own right. In view of the above remarks about the negative effects of relying exclusively on sectarian categories, one may offer the suggestion that the boundaries should be set with the explicit purpose of avoiding this pitfall. As long as we are not bound to accepting the sectarian normative views about how certain lineages are more authentically "Zen" than the others, such enlarged boundaries could comprise:

- Lineages that self-identify as belonging to any form of Chan tradition (suspending our judgment about whether this self-identification is justified or not).

- Buddhist forms of cultivation that include a specific emphasis on meditation, be it as the fifth perfection (Sk. dhyāna-pāramitā) or as a distinctive practice (such as the Tiantai practice of calming and insight, Sk. śamatha-vipaśyana).

- Other Asian religious disciplines aimed at training the mind to be "focused on one point" (Sk. ekagrātā).

The last item suggests going beyond the confines of traditional Buddhist Studies and taking into account interactions with non-Buddhist approaches that occurred throughout Buddhist history, in India, in China, and in other parts of Asia. ${ }^{9}$ Overall, what appears crucial is a clear awareness of the distinction between zen indicating a form of cultivation and the resulting meditative absorption, and Zen indicating various lineages claiming Bodhidharma as their common ancestor. In the second case, it is preferable to be specific and to speak of the Sōtō (Ch. Caodong), Rinzai (Ch. Linji), or Ōbaku (an offshoot of the Linji lineage) traditions. The English words "school, tradition, lineage, and sect" can almost be used interchangeably for these religious entities, but one may prefer to keep the word "denomination" to indicate the present institutions, whose legal recognition in Japan goes back only to 1872. In Korea the situation is slightly different because of the predominant position of the Jogye Order after the end of the Japanese occupation.

\section{Trends Since 1989 and Emerging Perspectives}

The delimiter of 1989 obviously serves to circumscribe our review to a manageable time range, but its choice is not arbitrary. The intense year of 1989 saw at least three events that can be singled out as turning points: the fall of the Berlin Wall, the Tian'anmen Square protest and its repression, and the attribution of the Nobel Peace Prize to the 14th Dalai Lama. In the area of Buddhist scholarship, it coincided with the publication of Robert Buswell's work, The Formation of Ch'an Ideology in China and Korea: The Vajrasamādhi-Sütra, a Buddhist Apocryphon. This erudite piece marked a watershed in Zen Studies, not only because it presented an early example of the intelligent application of critical scholarship to the field, but also because it contributed to widening its perspective. In his Preface, Buswell emphasized the need for contextualization, saying that "it is no longer tenable to treat East Asian Buddhism in terms of its separate national traditions" (Buswell Jr. 1989, p. xiv). This was a polite way to suggest that the bias toward Japanese Zen had distorted our perceptions for too long. Since then, Buswell's publications have contributed to redress this imbalance by showing the consistency of the Korean tradition, for example in his Zen Monastic Experience (Buswell Jr. 1992). 
This type of critical distance was taken one step further in two books by Bernard Faure, The Rhetoric of Immediacy: A Cultural Critique of Chan/Zen Buddhism (1991) and Chan Insights and Oversights: An Epistemological Critique of the Chan Tradition (1993). The innovation was to examine Chan and Zen from a perspective including the whole gamut of philosophy, sociology, and social sciences in general. It introduced in particular the thought of Jacques Derrida (1930-2004) and the sociological approach of Pierre Bourdieu (1930-2002), in a bold attempt to apply postmodernist strategies to the Buddhist traditions. These two volumes explored new territory and changed the way Zen Studies were to be conducted henceforth, because they utilized approaches that had never been applied to these traditions and featured untapped sources.

In a unique mix of praise and criticism Griffith Foulk concluded his review of Faure's work by stating that, "[d]espite its conceptual ambiguities and historiographical lapses, The Rhetoric of Immediacy is one of the most stimulating and challenging books ever written about East Asian Buddhism" (Foulk 1992, p. 526). Because of the theoretical nature of the book, Foulk complained that "Faure's sociological interpretations are largely abstract observations, divorced from concrete textual or historical examples" (Foulk 1992, p. 522), but overall Faure's work contributed to show how the Zen traditions can be problematized, and how previous scholarship had been short-sighted in its unilateral reliance on sources produced within the lineages it purported to discuss. Of course, Faure's research did not stop with these two volumes and thereafter he has produced a steady stream of intellectually stimulating pieces, but the aforementioned twin books have become almost required readings for graduate students and scholars alike. Speaking of new trends, one may even contend that western Zen scholarship produced after the 1990s is being automatically submitted to the test of the Faurian epistemological critique.

In this regard, epistemological concerns play an increasingly pivotal role. How do we acquire knowledge about Chan or Zen? Can we exclusively rely on textual sources produced by a small fraction of the religious elite, or should we at least attempt to diversify the channels of information by including non-textual resources and listening to less privileged voices? On the other hand, going too far in the direction of deconstructing the tradition's self-representations may be verging on reductionism. This dilemma has been addressed by Steven Heine, who surveyed Zen Studies between 1967 and 2007 (Heine 2007) and then attempted to draw a line between what he calls the "traditional Zen narrative" and "historical cultural criticism" (Heine 2008). Here, the delicate issue is that these two categories do not result from different scholarly approaches, but rather constitute discrete world-views: the former produced by religious practitioners, the latter by the academic community. Heine displays considerable talent in trying to find a rejoinder but - in spite of the significant number of American scholars who also wear the hat of Buddhist practitioners - the likelihood of finding common ground between the rosy narrative and the critical account seems rather slim. ${ }^{90}$

While for a long time the tendency to uncritically accept romantic accounts of Zen prevailed, since the 1990s the opposite tendency has become conspicuous, at least in scholarly circles. We are thus in the midst of what could be characterized as the demythologization $^{11}$ of Zen, which still does not seem to have reached the public. This delay might be the result of a conscious or unconscious resistance to the idea that Zen Studies and their object are no more immune to criticism, a form of "parochialism" akin to the instinctive reaction to any paradigm shift challenging one's beliefs. Whatever the reason, we cannot deny that the majority of "Zen" publications garnishing the shelves of bookstores keep replicating the same worn-out Zen narratives ad nauseam, and that some university classes also contribute to perpetuate them. 
On the opposite side of the spectrum, Dale Wright's Philosophical Meditations on Zen Buddhism (1998) shows the magnitude of the shift accomplished by recent scholarship. Wright scrutinizes with great tact romantic inclinations toward Zen and their projections onto the particular figure of the Chan patriarch Huangbo. In the same vein John McRae's Seeing through Zen (2003) articulates concrete measures to redress this tendency. Despite the usefulness of such publications, students who read them are sometimes puzzled by the fact that these reflections partially reflect the author's own journey from an early romanticized acquaintance with Zen literature to the critical viewpoint of a mature scholar. Moving directly into the critical phase without having experienced the earlier fascination may be difficult for less mature readers, but reviewing the preceding romantic phase often allows to overcome this initial obstacle.

A similar pedagogical issue may occur when unwary students wade through publications criticizing Zen and Buddhism in a more radical way. The crucial issues of Japanese Zen's collusion with nationalism and war collaboration were scrutinized by Robert Sharf in a series of articles beginning with "The Zen of Japanese Nationalism" (Sharf 1993) and its 1994 sequel (Sharf 1994), eventually reprinted in an edited volume (Sharf 1995b). Sharf further explored the Sanbōkyōdan movement (Sharf 1995a) and the way "experience" had been utilized to promote Japanese Zen (Sharf 1995c). This line of inquiry was followed by Brian Victoria, who developed it into a kind of indictment in his Zen at War (Victoria 1997). This work was translated into several languages including Japanese, and has already been republished (Victoria 2006). Victoria wrote a second volume denouncing the clergy's involvement in the war, devoting more attention to individual cases (Victoria 2003). Considerable work remains to be done, however, to determine the degree to which each of these individual figures really endorsed violence. One attempt to contextualize the particular case of Shaku Sōen resulted in the chapter "The Use of Traps and Snares" (Mohr 2010). Some of the work accomplished by a minority of Japanese scholars to denounce the Buddhist war collaboration has been examined by Christopher Ives in his Imperial-Way Zen (Ives 2009). Lifting the lid on how violence could be condoned by the Buddhist clergy led to a surge of interest in the topic, with the publication of a volume on Buddhism and Violence (Zimmermann et al. 2006), followed by Buddhist Warfare (Jerryson \& Juergensmeyer 2010). These publications do not focus exclusively on Chan or Zen, but contain chapters relevant to these traditions as well, including additional research by Victoria. Although not focused on Zen, the meticulous historical analysis of Mikael Adolphson in The Teeth and Claws of the Buddha: Monastic Warriors and Sōhei in Japanese History is also relevant to this debate (Adolphson 2007).

We thus begin to have a growing arsenal of tools - which are not necessarily lenient toward the traditions they analyze - indicating how the scholarly landscape has changed since the 1990s. Students who used to take for granted that Zen represents the apex of non-violence tend to be initially baffled when realizing the extent of dark areas within the actual history of the Buddhist schools. Then, as they discover the varieties and nuances of Religious Studies and incorporate a more critical handling of the sources, they usually become aware of the need not to throw out the baby with the bathwater. In this regard, one should ask whether the best approach is to let student begin their study of Zen by coping with its more unpleasant side from the outset. From a pedagogical perspective, once the basics about Buddhist history and doctrine have been digested, one may rather suggest to start a deeper exploration by reading modern scholarship focused on specific themes within the Zen tradition.

Although they do not constitute introductory volumes, the series edited by Steven Heine and Dale Wright may fulfill this role. They include anthologies on The Kōan (2000), The Zen Canon (2004), Zen Classics (2006), Zen Ritual (2008), and Zen Masters 
(2010). For those more specifically interested in the Tokugawa period, Duncan Williams's The Other Side of Zen (Williams 2005) is excellent. For a thematic work focusing on the Meiji period beyond the confines of Zen, Richard Jaffe's Neither Monk nor Layman (Jaffe 2001) provides a wealth of information revolving around the issue of clerical marriage. Advanced students looking for a sophisticated approach questioning the traditional chronological and religious categories will appreciate Janine Sawada's Practical Pursuits (Sawada 2004). There is no room here to discuss examples of studies focusing on particular Zen figures such as Dōgen, Keizan, Ikkyū, Bankei, Hakuin, or Ryōkan. Students wishing to understand developments specific to the Sōtō school can begin with the solid work of William Bodiford (Bodiford 1993) and Carl Bielefeldt (Bielefeldt 1988). At this point one cannot fail to mention research on the Öbaku tradition, the most neglected among the present Japanese denominations. Fortunately, Helen Baroni's Obaku Zen (Baroni 2000) and Iron Eyes (Baroni 2006) have contributed to point out this tradition's role as an earlymodern bridge to Chinese Buddhism. Awareness of the importance of Ōbaku as a multicultural phenomenon has been reinforced by James Baskind's dissertation, Ming Buddhism in Edo Japan: The Chinese Founding Masters of the Japanese Obaku School (Baskind 2006), but this remains an area deserving more attention. Let us now mention some of the leading publications dealing with China, Korea, and Vietnam.

The encouraging trend is the emergence of studies concentrating on particular phases in the development of Chan. Concerning the Tang dynasty, significant advances have been summarized in recent publications including Jinhua Jia's The Hongzhou School of Chan Buddhism in Eighth- through Tenth-Century China (Jia 2006), Mario Poceski's Ordinary Mind as the Way (Poceski 2007), and Wendi Adamek's The Mystique of Transmission: On an Early Chan History and Its Contexts (Adamek 2007). James Robson's Power of Place: The Religious Landscape of the Southern Sacred Peak (Nanyue) in Medieval China (Robson 2009) focuses on one specific location crucial to Chan, Tang Buddhism in general, and Daoism.

The Sung dynasty is also receiving increasing attention as Chan's formative period. In addition to the important anthology entitled Buddhism in the Sung (Gregory \& Getz 1999), advances in this area include various chapters included in the above-mentioned volumes, and an in-depth study by Morten Schlütter (Schlütter 2008). We finally also have an accessible study dealing with the neglected Ming period, thanks to the publication of Jiang Wu's Enlightenment in Dispute (Wu 2008).

Unfortunately, Korea and Vietnam remain less popular in Zen scholarship, simply because fewer scholars have access to these languages. Aside from Buswell's The Zen Monastic Experience: Buddhist Practice in Contemporary Korea (1992) already mentioned, and of publications focusing on the works of Chinul (see in particular Chinul \& Buswell 1983), Charles Muller has provided access to the traditional exegesis of Kihwa's commentary on The Sutra of Perfect Enlightenment (Muller 1999). Contemporary developments are also being investigated, with Chanju Mun's analysis of the Korean Buddhist movement aiming at returning to its pre-war "purity" (Mun 2011). Concerning Vietnam, the range of available publications remains dominated by the prolific output of Nhat Hanh, but more academic publications are slowly emerging, including Cuong Tu Nguyen's Zen in Medieval Vietnam (Nguyen 1997a) and Tai Thu Nguyen's more general History of Buddhism in Vietnam (Nguyen 1997b). Much remains to be investigated not only by highlighting these specific areas, but also by examining the transnational dimension of Korean Seon and Vietnamese Thiên.

Speaking of transnational developments, the transmission of Buddhism to the West is gathering considerable attention, with some publications of high caliber including Stephen Prothero's The White Buddhist (Prothero 1996) and Thomas Tweed's The American 
Encounter with Buddhism 1844-1912 (Tweed 1992, 2000), who also made crucial discoveries about the background of D. T. Suzuki (Tweed 2005). The focus has even turned more specifically on American Buddhism in two edited volumes (Prebish \& Tanaka 1998; Williams \& Queen 1999). Let us now return to the broader picture.

\section{Prospects and New Perspectives}

However tempting, periodizing the development of Zen Studies inevitably involves oversimplification. Let me nevertheless attempt to distinguish four phases, which illustrate some of its most significant shifts:

1. Early Accounts $(-1892)$

2. Discovery Phase (1893-1957)

3. Fascination Phase (1958-1988)

4. Detachment Phase (1989-present).

Because this paper focuses on post-1989 developments, the previous three phases have not been discussed. Strictly speaking, the early accounts do not belong to "Zen Studies" per se, but they already embed some of the biases informing the early discovery of Zen and Buddhism in general. We now have a series of in-depth analyses by Urs App (App 2009, 2010a,b), which show how the initial discovery phase beginning in the 16th century predated the colonial enterprise and the more sophisticated distortions generated by Orientalism in the wake of systematic colonization. For the delimiter between phase 1 and phase 2, I arbitrarily chose the date of the World Parliament of Religions in Chicago (1893), which coincides with the first representation of Zen outside of Asia. Again, this could hardly be considered the beginning of Zen Studies as a field, and Shaku Sōen gave a discourse exclusively focused on Mahāyāna, ${ }^{12}$ but it marks a new phase in the degree of visibility of Zen in scholarship.

Hitherto, I have been referring to the third phase as the time during which the romanticized version of Zen prevailed, but Patricia Vessie - who was writing in the midst of that time - identified it less ambiguously as the juncture at which it became a "fad":

Popular response reached a peak in the late 1950s in the United States with the Beatniks, J. D. Salinger's short stories and Jack Kerouac's novels. At the same time, psychoanalysts Erich Fromm, Carl Jung and Karen Horney explored Zen for therapeutic possibilities and Alan Watts was writing, lecturing and televising for wide audiences. Zen was an American fad. (Vessie 1976, p. viii)

The fourth phase should not be confused with estrangement, in the sense that, without playing on words, detachment can prove beneficial. It would be inaccurate to pretend to identify phases valid everywhere and across all social strata, however. We need to look at carefully defined segments of specific populations, even within a single society. Aside from variations in the public, as mentioned above, academics in Japan and academics in North American or European institutions also often face significantly different expectations, not to speak of the institutions' own nature and structure (for instance, many private universities in Japan are financed by religious institutions, which in turn inform the field's inclinations).

If Zen Studies is presently in the midst of a "detachment phase," as this article, written in fall 2011 argues, what could be the consequences in the foreseeable future? The first obvious reply is that many of the benefits of such detachment for a healthier and more comprehensive understanding of the topic still need to be reaped. This new phase has just 
started, and it would be premature to celebrate the newly acquired independence of a few scholars. For one thing, the majority of research produced in Asia still comes from institutions belonging to specific denominations and is informed by traditional sectarian studies (shīgaku in Japanese). Thus, there is plenty of room for additional research that strikes a good balance between critical scholarship and a careful usage of primary sources, and one may expect such work to become more common, especially in scholarly circles free from the sectarian yoke.

In relation to primary sources, one cannot overemphasize the dearth of reliable translations of Chan and Zen texts. Some professional translators have done extensive damage to the field by feeding hasty translations to the public, sometimes without even mentioning the source materials on which their work is based. Many of these publications need to be retranslated from scratch and properly contextualized, providing the scholarly apparatus that allows students to navigate in the maze of intertextuality. Although it tends not be very popular these days, one of the major contributions that $\mathrm{PhD}$ dissertations can make to their respective fields is precisely to provide meticulous research including careful translation.

The accurate translation of a classic can lead to new scrutiny, as illustrated by Albert Welter's work on The Linji lu and the Creation of Chan Orthodoxy (Welter 2008). With the publication of the same text's annotated translation by Ruth Fuller Sasaki and her team (Kirchner 2009), and with Christopher Ives's presentation of a traditional exegesis, Critical Sermons of the Zen Tradition: Hisamatsu's Talks on Linji (Hisamatsu et al. 2002), Linji's sayings are now equipped for fresh investigation.

Without speculating about future developments, it is possible to reason in terms of needs. As far as Chan and Zen research is concerned, three needs immediately come to mind: more works focused on precise case studies, integration within wider frameworks, and investigation of marginal figures. There is an enormous amount of archival material that remains dormant in temples' storage rooms, but only the painstaking work of dealing with primary sources can exhume their potential message. Even if we were to discuss only printed sources, the proportion of those carefully studied and translated probably does not exceed 5\%. In this regard, a huge amount of labor is still needed in inputting and editing source materials that do not belong to the main Buddhist canons. Although digitization has already affected all scholarly disciplines including Zen Studies, and contributes to facilitate lexical research, it also has the side effect of potentially leading to the neglect of materials that fall under the radar of digital searches.

\section{$V$. Concluding Remarks}

This survey article suggests the existence of a field or subfield that we may choose to label Zen Studies, although its boundaries are still fluctuating. I argued that it should be expanded within reasonable limits and that the sectarian criterion should not serve as a reliable guideline. Another emerging feature is that barely more than two decades have elapsed since the emergence of a seriously critical and epistemologically aware trend within this field. Consequently, methodological concerns remain in their infancy. Some degree of concerted effort among scholars to think about methodological issues is just burgeoning, but it needs to be enriched by taking into account similar advances in neighboring fields. The results of these reflections will need to be skillfully distilled to non-academic audiences, a development that remains almost nonexistent. More than ever, studies challenging received ideas and closer collaboration between scholars are needed to keep not only raising the standards of the academic study of Zen but also to come to terms with its past stigma of an ephemeral fashion. Those eager to further plow 
this field need to carefully investigate existing trenches and trends in scholarship, which are in need of being fertilized with new insights.

\section{Short Biography}

Michel Mohr presently works at the University of Hawai'i as Associate Professor in the Department of Religion. After obtaining a doctorate from the University of Geneva (Switzerland), he has spent almost 20 years in Kyoto doing research on Japanese Buddhism and Zen in particular. His recent publications include the chapters "The Use of Traps and Snares: Shaku Sōen Revisited," in Zen Masters (Oxford: Oxford University Press, 2010), "Invocation of the Sage: The Ritual to Glorify the Emperor," in Zen Ritual: Studies of Zen Buddhist Theory in Practice (Oxford: Oxford University Press, 2008), and the article "Murakami Senshō: In Search of the Fundamental Unity of Buddhism," in The Eastern Buddhist 37/1-2. For current research projects and his latest publications in English, Japanese, and French, please consult his personal website: http://michelmohr. com.

\section{Notes}

* Correspondence address: Department of Religion, University of Hawai'i, Michel Mohr, 2530 Dole Street, Sakamaki Hall, Honolulu, HI 96822, USA.

1 The word "meditation" can be applied to the Buddhist context as long as it is understood in its pseudoetymological sense of "(re-)centering" the mind, corresponding to one of its Indian definitions as the mind "focused on one point" (Sk. ekagrätâ). It should also be pointed out that the object of this concentration often is understood as being non-discursive, meaning that the objective is to empty the mind of its ratiocinations rather than to add new ones.

2 Almost a year elapsed between the end of the Tokugawa regime, which coincides with the resignation of the last shogun Tokugawa Yoshinobu (1837-1913) on the 14th day of the 10th month in the third year of the Keio era (November 9, 1867), and the beginning of the new Meiji era (1868-1912) on the 8th day of the 9th month of Keiō 4 (October 23, 1868).

3 A third avenue would be to explore the popular meaning of "zen" in the West as a concept disconnected from religion. Such exploration goes beyond the scope of this article, but let us simply mention the fascinating use of the word "zen" as a commodity in the marketplace. The place of this mutation of "zen" in the mass media and in commercial settings constitutes another area worth of anthrolopological scrutiny.

4 He seems to have used Magadhi Prakrit, the vernacular language prevalent in the Magadha kingdom.

5 Zürcher (1991, p. 282) puts "the first unquestionable sign of Buddhism in China" in 65 CE.

6 Indian descriptions of the various stages of meditation usually include nine meditative states beginning with the four jhänas (often translated as "absorptions" or "enstasis"), followed by the four samapattis or "formless states." They culminate in the ninth stage of cessation of perception and feeling, also known as the attainment of cessation (Sk. nirodha-samāpatti). For further details, see Griffiths (1993) and Mohr (2005).

7 Concerning earlier sources, see Broughton (1999).

8 The work of Christoph Anderl provides useful signposts and further references (Anderl 2004, 2006, 2012).

9 One in-depth publication examining interactions with Daoism is Mollier (2008). The issue of Japanese combinative religiosity has been skillfully analyzed by Allan Grapard in his Protocol of the Gods (Grapard 1992).

10 To dispel potential misunderstanding, I do not mean here that the practitioners' perspective is necessarily incompatible with that of scholars. Many scholars have found ways to reconcile both in their own lives. The incompatibility is between a romanticized version of a given tradition and the critical recognition of its possible limitations.

11 Reference to the German theologian Rudolf Karl Bultmann (1884-1976).

12 See Mohr (2010, pp. 192-5).

\section{Works Cited}

Adamek, Wendi Leigh. (2007). The Mystique of Transmission: On an Early Chan History and Its Contexts. New York: Columbia University Press. 
Adolphson, Mikael S. (2007). The Teeth and Claws of the Buddha: Monastic Warriors and Sohei in Japanese History. Honolulu: University of Hawai'i Press.

Anderl, Christoph. (2004). Studies in the Language of Zu-Tang ji, vols. 2. PhD dissertation, Oslo University.

- (2006). Zen in the Art of Insult: Notes on the Syntax and Semantics of Abusive Speech in Late Middle Chinese. In: Christoph Anderl and Halvor Eifring (eds.), Studies in Chinese Language and Culture: Festschrift in Honour of Christoph Harbsmeier on the Occasion of his 60th Birthday, pp. 377-91. Oslo: Hermes Academic Publishing.

App, Urs. (2009). William Jones's Ancient Theology. Philadelphia: Department of East Asian Languages and Civilizations.

—. (2010a). The Birth of Orientalism. Philadelphia: University of Pennsylvania Press.

. (2010b). Arthur Schopenhauer and China: A Sino-Platonic Love Affair. Philadelphia: Department of East Asian Languages and Civilizations.

Baroni, Helen Josephine. (2000). Obaku Zen: The Emergence of the Third Sect of Zen in Tokugawa Japan. Honolulu: University of Hawai'i Press.

. (2006). Iron Eyes: The Life and Teachings of the Öbaku Zen Master Tetsugen Dōkō. Albany, NY: State University of New York Press.

Baskind, James Matthew. (2006). Ming Buddhism in Edo Japan: The Chinese Founding Masters of the Japanese Obaku School. PhD dissertation, Yale University.

Bielefeldt, Carl. (1988). Dōgen's Manuals of Zen Meditation. Berkeley: University of California Press.

Bodiford, William M. (1993). Sōtō Zen in Medieval Japan. Honolulu: University of Hawai'i Press.

Broughton, Jeffrey L. (1999). The Bodhidharma Anthology: The Earliest Records of Zen. Berkeley, CA: University of California Press.

Buswell, Robert E. Jr. (1989). The Formation of Ch'an Ideology in China and Korea: The Vajrasamādhi-Sūtra, A Buddhist Apocryphon. Princeton, NJ: Princeton University Press.

—. (1992). The Zen Monastic Experience: Buddhist Practice in Contemporary Korea. Princeton NJ: Princeton University Press.

Chinul \& Buswell, Robert E. (1983). The Korean Approach to Zen: The Collected Works of Chinul. Honolulu: University of Hawai'i Press.

Cole, Alan. (2009). Fathering Your Father: The Zen of Fabrication in Tang Buddhism. Berkeley, CA: University of California Press.

Foulk, Griffith T. (1992). Ineffable Words, Unmentionable Deeds, Monumenta Nipponica, 47(4), pp. 521-6.

Gardner, James L. (1991). Zen Buddhism: A Classified Bibliography. Salt Lake City: Wings of Fire Press.

Grapard, Allan G. (1992). The Protocol of the Gods: A Study of the Kasuga Cult in Japanese History. Berkeley and Los Angeles: University of California Press.

Gregory, Peter N. \& Getz, Daniel A. Jr. (eds.) (1999). Buddhism in the Sung. Honolulu: University of Hawai'i Press.

Griffiths, Paul J. (1993). Indian Buddhist Meditation. In: Yoshinori Takeuchi and Jan van Bragt (eds.), Buddhist Spirituality: Indian, Southeast Asian, Tibetan, and Early Chinese, pp. 34-66. New York: Crossroad.

Heine, Steven. (2007). A Critical Survey of Works on Zen Since Yampolsky, Philosophy East and West, 57, pp. 577-92.

- (2008). Zen Skin, Zen Marrow: Will the Real Zen Buddhism Please Stand Up. Oxford; New York: Oxford University Press.

Hisamatsu, Shin'ichi, Tokiwa, Gishin \& Ives, Christopher. (2002). Critical Sermons of the Zen Tradition: Hisamatsu's Talks on Linji. Honolulu: University of Hawai'i Press.

Ives, Christopher. (2009). Imperial-Way Zen: Ichikawa Hakugen's Critique and Lingering Questions for Buddhist Ethics. Honolulu: University of Hawai'i Press.

Jaffe, Richard M. (2001). Neither Monk nor Layman: Clerical Marriage in Modern Japanese Buddhism. Princeton, NJ: Princeton University Press.

Jerryson, Michael K. \& Juergensmeyer, Mark (eds.) (2010). Buddhist Warfare. New York: Oxford University Press.

Jia, Jinhua. (2006). The Hongzhou School of Chan Buddhism in Eighth- Through Tenth-Century China. Albany, NY: State University of New York Press.

Kirchner, Thomas Yūhō (ed.) (2009). The Record of Linji. Honolulu: University of Hawai'i Press.

McRae, John R. (2003). Seeing Through Zen: Encounter, Transformation, and Genealogy in Chinese Chan Buddhism. Berkeley: University of California Press.

Mohr, Michel. (2005). Chan and Zen. In: Donald Borchert (ed.), The Encyclopedia of Philosophy, 2nd edn., pp. 72630. Detroit: Macmillan Reference, Gale Group/Thomson.

- (2010). The Use of Traps and Snares: Shaku Sōen Revisited. In: Steven Heine and Dale Stuart Wright (eds.), Zen Masters, pp. 183-216. New York: Oxford University Press.

Mollier, Christine. (2008). Buddhism and Taoism Face to Face: Scripture, Ritual, and Iconographic Exchange in Medieval China. Honolulu: University of Hawai'i Press.

Muller, Charles A. (1999). The Sutra of Perfect Enlightenment: Korean Buddhism's Guide to Meditation (With Commentary by the Son Monk Kihwa). New York: State University of New York Press. 
Mun, Chanju. (2011). Purification Buddhist Movement, 1954-1970: The Struggle to Restore Celibacy in the Jogye Order of Korean Buddhism. Honolulu, HI: Blue Pine Books.

Nguyen, Cuong Tu. (1997a). Zen in Medieval Vietnam: A Study and Translation of the Thien Uyen Tap Anh. Honolulu: University of Hawai'i Press.

Nguyen, Tai Thu. (1997b). History of Buddhism in Vietnam. Washington, D.C.: Council for Research in Values and Philosophy.

Poceski, Mario. (2007). Ordinary Mind as the Way: The Hongzhou School and the Growth of Chan Buddhism. Oxford; New York: Oxford University Press.

Prebish, Charles S. \& Tanaka, Kenneth Ken'ichi (eds.) (1998). The Faces of Buddhism in America. Berkeley: University of California Press.

Prothero, Stephen R. (1996). The White Buddhist: The Asian Odyssey of Henry Steel Olcott. Bloomington: Indiana University Press.

Robson, James. (2009). Power of Place: The Religious Landscape of the Southern Sacred Peak (Nanyue) in Medieval China. Cambridge: Harvard University Asia Center.

Sawada, Janine Tasca. (2004). Practical Pursuits: Religion, Politics, and Personal Cultivation in Nineteenth-Century Japan. Honolulu: University of Hawai'i Press.

Schlütter, Morten. (2008). How Zen Became Zen: The Dispute Over Enlightenment and the Formation of Chan Buddhism in Song-Dynasty China. Honolulu: University of Hawai'i Press.

Sharf, Robert H. (1993). 'The Zen of Japanese Nationalism, History of Religions, 33, pp. 287-96.

- (1994). Whose Zen? Zen Nationalism Revisited. In: James W. Heisig and John C. Maraldo (eds.), Rude Awakenings: Zen, the Kyoto School, \& the Question of Nationalism, pp. 40-51. Honolulu: University of Hawai' $\mathrm{i}$ Press.

- (1995a). Sanbōkyōdan: Zen and the Way of the New Religions, Japanese Journal of Religious Studies, 22, pp. 417-58.

- (1995b). The Zen of Japanese Nationalism. In: Donald S. Lopez Jr. (ed.), Curators of the Buddha: The Study of Buddhism Under Colonialism, pp. 107-60. Chicago: The University of Chicago Press.

- (1995c). Buddhist Modernism and the Rhetoric of Meditative Experience, Numen, 42, pp. $228-83$.

Tweed, Thomas A. (1992). The American Encounter With Buddhism 1844-1912: Victorian Culture and the Limits of Dissidents. Bloomington and Indianapolis: Indiana University Press.

- (2000). The American Encounter With Buddhism, 1844-1912: Victorian Culture \& the Limits of Dissent. Chapel Hill, NC: University of North Carolina Press.

- (2005). American Occultism and Japanese Buddhism: Albert J. Edmunds, D. T. Suzuki, and Translocative History, Japanese Journal of Religious Studies, 32, pp. 249-81.

Vessie, Patricia Armstrong. (1976). Zen Buddhism: A Bibliography of Books and Articles in English, 1892 -1975. Ann Arbor, MI: University Microfilms International.

Victoria, Brian Daizen. (1997). Zen at War. New York and Tokyo: Weatherhill.

- (2003). Zen War Stories. London; New York: Routledge Curzon.

- (2006). Zen at War. Lanham, MD: Rowman \& Littlefield Publishers.

Welter, Albert. (2008). The Linji lu and the Creation of Chan Orthodoxy: The Development of Chan's Records of Sayings Literature. Oxford; New York: Oxford University Press.

Williams, Duncan Ryūken. (2005). The Other Side of Zen: A Social History of Sōtō Zen Buddhism in Tokugawa Japan. Princeton, NJ: Princeton University Press.

— \& Queen, Christopher S. (eds.) (1999). American Buddhism: Methods and Findings in Recent Scholarship. Richmond, Surrey, UK: Curzon.

Wu, Jiang. (2008). Enlightenment in Dispute: The Reinvention of Chan Buddhism in Seventeenth-Century China. Oxford; New York: Oxford University Press.

Zimmermann, Michael, Chiew, Hui Ho \& Pierce, Philip (eds.) (2006). Buddhism and Violence. Lumbini: Lumbini International Research Institute.

Zürcher, Erik. (1991). A New Look at the Earliest Chinese Buddhist Texts. In: Koichi Shinohara and Gregory Schopen (eds.), From Benares to Beijing: Essays on Buddhism and Chinese Religion, pp. 277-304. Oakville, New York, London: Mosaic Press.

\section{Further Reading}

Anderl, Christoph. (ed.) (2012). Zen Buddhist Rhetoric in China, Korea, and Japan. Leiden; Boston: Brill.

App, Urs. (1993). A Bibliography of Recent English Publications on Chan / Zen / Son Buddhism (1977-1992), Zenbunka kenkyū kiyō, 19, pp. 1-58.

- (1994). Reference Works for Chan Research, Cahiers d'Extrême-Asie, 7, pp. 357-409.

Borup, Jørn. (2008). Japanese Rinzai Zen Buddhism: Myōshinji, a Living Religion. Leiden \& Boston: Brill Academic Publishers. 